\title{
Does Socioeconomic Status Matter? A Meta- Analysis on Parent Training Effectiveness for Disruptive Child Behavior
}

Patty Leijten, Maartje A. J. Raaijmakers , Bram Orobio de Castro \& Walter Matthys

To cite this article: Patty Leijten, Maartje A. J. Raaijmakers, Bram Orobio de Castro \& Walter Matthys (2013) Does Socioeconomic Status Matter? A Meta-Analysis on Parent Training Effectiveness for Disruptive Child Behavior, Journal of Clinical Child \& Adolescent Psychology, 42:3, 384-392, DOI: 10.1080/15374416.2013.769169

To link to this article: https://doi.org/10.1080/15374416.2013.769169

曲 Published online: 05 Mar 2013.

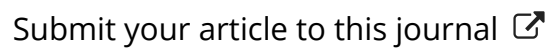

Џll Article views: 1613

Citing articles: 63 View citing articles 4 


\title{
Does Socioeconomic Status Matter? A Meta-Analysis on Parent Training Effectiveness for Disruptive Child Behavior
}

\author{
Patty Leijten, Maartje A. J. Raaijmakers, and Bram Orobio de Castro \\ Department of Psychology, Utrecht University \\ Walter Matthys \\ Department of Child and Adolescent Studies, Utrecht University and \\ Department of Psychiatry, University Medical Center, Utrecht
}

\begin{abstract}
Disadvantaged family socioeconomic status (SES) is often assumed to diminish parent training program effectiveness. In examining effects of SES, influences of initial problem severity have been largely ignored. In the present meta-analysis, we examined (a) whether there is a differential influence of SES on parent training effectiveness at immediate posttreatment and at 1-year follow-up - controlling for levels of initial problem severity - and (b) whether SES interacts with initial problem severity in its effect on program effectiveness. Seventy-five studies on parent training program effectiveness to reduce disruptive child behavior were included. Separate analyses were conducted for immediate posttreatment and approximately 1-year follow-up assessments. Immediately posttreatment, disadvantaged samples benefited less from parent training, but only when they had low levels of initial problem severity. At follow-up, disadvantaged samples benefited less from parent training regardless of initial problem severity. Initial problem severity was a strong predictor of effect sizes both immediately posttreatment and at follow-up. Parent training programs are equally effective for disadvantaged and nondisadvantaged families immediately posttreatment, at least when initial problems are severe. Maintenance of treatment gain, however, seems harder for disadvantaged families, suggesting that more sustained family support may be needed.
\end{abstract}

Meta-analyses show that parent training programs are an effective method to reduce disruptive child behavior (e.g., McCart, Priester, Davies, \& Azen, 2006; Serketich \& Dumas, 1996). For some families, that is-not all families benefit equally from parent training programs (e.g., Lundahl, Risser, \& Lovejoy, 2006). One factor that is often assumed to influence parent training effectiveness is family socioeconomic status (SES). In particular, socially and economically disadvantaged families are assumed to benefit less from parent training programs than nondisadvantaged families. These families' financial, psychological, or social stressors may limit their

Correspondence should be addressed to Patty Leijten, Department of Psychology, Utrecht University, P.O. Box 80140, 3584 CS, Utrecht, The Netherlands. E-mail: P.H.O.Leijten@uu.nl potential for positive change (Conger et al., 1992) Although there are some exceptions showing opposite results (e.g., Deković et al., 2011; Gardner, Hutchings, Bywater, \& Whitaker, 2010; MacKenzie, Fite, \& Bates, 2004), studies have generally supported the view that disadvantaged families benefit less from parent training programs (e.g., Lundahl et al., 2006). In addition, there are indications that effects of SES are influenced by program characteristics such as that disadvantaged families benefit more from individual than group delivery (Lundahl et al., 2006).

A well-known strong predictor of parent training effectiveness that has been largely ignored in previous meta-analyses on effects of SES on parent training effectiveness is the severity of children's disruptive behavior 
problems at baseline (i.e., before the start of the intervention). Treatment studies in clinical samples generally obtain stronger effects than preventive studies in nonclinical community samples (Weisz, Sandler, Durlak, \& Anton, 2005). This same pattern of results can be found in single studies, in which families with high initial levels of behavior problems typically benefit more from parent training programs than families with low initial levels of behavior problems (e.g., Hautmann et al., 2010). Parents may be more motivated to get the best out of the training when they experience their child's behavior as more problematic. Parental motivation and "readiness to change" strongly influence the positive impact that parent training programs can exert, for example, through higher attendance and adherence rates (Baydar, Reid, \& Webster-Stratton, 2003; Miller \& Rollnick, 2002). In addition, more severely troubled children have a larger scope for improvement. As a result, larger intervention effects can more easily be obtained in children with higher levels of initial problem severity.

Although perhaps of influence for all families, initial problem severity may be especially important for parent training effectiveness in disadvantaged families. Disruptive problem behaviors are more strongly associated with problematic parenting practices in disadvantaged families, which often have smaller social networks and less access to resources to provide them with parenting assistance and advice (Bradley, Corwyn, Burchinal, McAdoo, \& Garcia-Coll, 2001; Evans, Boxhill, \& Pinkava, 2010; Schonberg \& Shaw, 2007; Wadsworth $\&$ Achenbach, 2005). Therefore, parent training programs directly targeted at the improvement of parenting skills may be able to obtain especially large improvements in disadvantaged families with high levels of initial problem severity.

Previous meta-analyses suggest that SES may differentially impact parent training effectiveness measured at immediate posttreatment (i.e., within a few weeks after the end of the program; e.g., McCart et al., 2006) than at follow-up (i.e., months or even years later; e.g., Deković et al., 2011). In particular, although disadvantaged families may already show less improvement immediately posttreatment, their limited treatment responsiveness may become especially salient at follow-up, when participants are thrown back on their own resources to maintain and further enhance positive changes. SES operates on families' lives in large part via chronic stressors that accompany low SES, such as poor parental mental health, social isolation, and deprived neighborhoods (Baum, Garofalo, \& Yali, 1999; Pinderhughes, Nix, Foster, \& Jones, 2001). So even though disadvantaged families may be able to reduce disruptive child behavior during the intervention, it may be an especially hard and enduring battle to maintain and extend improvements after the end of the program, in the light of the chronic stressors they face, and when support from trainers is no longer available. In the present meta-analysis, we therefore compared influences of SES and initial problem severity on the reduction of children's disruptive behavior problems immediately posttreatment (i.e., directly after preventive or treatment intervention) and at follow-up approximately one year later.

\section{METHOD}

\section{Literature Search}

Computer searches of PsycINFO and ERIC were conducted for all published studies until January 31, 2010. We used the following search terms in varying combinations: parent training, parenting program, disruptive, behavior problems, effectiveness, and efficacy. Studies were first filtered based on information in the abstracts. Only studies including an effectiveness study on reducing disruptive behavior problems were included for further examination. The 150 studies resulting from this selection were studied more closely and judged on the inclusion criteria (see next).

\section{Selection of Studies}

Studies were selected for inclusion if they (a) reported on the effectiveness of parent training programs targeting disruptive child behavior (up to the age of 12 years maximum), (b) had at least one treatment and one control group drawn from the same population, (c) had treatment and control groups larger than $N=5$, (d) involved multiple-session parent training (interventions consisting of only one session were excluded), (e) included families in which the targeted children were not developmentally or cognitively delayed, (f) reported means and standard deviations of disruptive behavior on a standardized measure, (g) were written in English, and (h) were published in peer-reviewed journals. These inclusion criteria resulted in 75 final studies. Thirteen studies included multiple intervention conditions that shared the same control condition, which may have resulted partially dependent data. However, multilevel meta-analytic analyses were not possible because the sample size of thirteen studies with nested data was too small (Maas \& Hox, 2005).

\section{Effect Size}

The outcome measure of our meta-analysis was the effect size of reduced parent-reported disruptive child behavior. We used intergroup Cohen's $d$ as the measure of effect size immediately posttreatment, where $d$ represents the difference in disruptive behavior reduction 
between intervention and control conditions expressed in standard deviation units (cf. Lipsey \& Wilson, 2001). For studies that reported multiple parent-reported measures of disruptive child behavior, the mean $d$ was computed.

Because most studies with follow-up assessments used a wait list control design (88\%) and therefore did not report follow-up data for the control condition, follow-up effect sizes were computed based on reduction of disruptive behavior within the intervention condition (i.e., intragroup effect sizes). Because not corrected for improvements in the control group, intragroup effect sizes typically are inflated. To illustrate, the eight studies for which intergroup effect sizes at follow-up could be calculated had a mean intergroup effect sizes of $d=.28$, compared to a mean intragroup effect size at follow-up of $d=.85$. Intragroup follow-up effect sizes can therefore be compared only with each other and not with immediately posttreatment intergroup effect sizes. If studies included multiple follow-up assessments, the assessment closest to 12 months was selected, because the majority of studies used a 12-month follow-up period.

\section{Moderators}

Socioeconomic status. Categorization was done by the studies' original authors. All authors were e-mailed with the request to define their study's sample as either disadvantaged or nondisadvantaged, based on local and (if applicable) historical, national standards of SES. Dichotomous categorization was used because there was no continuous measure (e.g., income, educational level) that was used in all studies alike. In addition, dichotomization is in line with several previous meta-analyses (e.g., Lundahl et al., 2006), which enables direct comparison of our results with previous findings. Seventy-eight percent of all authors sent in their categorization, which was based on their samples' educational level $(63 \%)$, income $(43 \%)$, Hollingshead index $(21 \%)$, occupational status $(21 \%)$, financial aid (12\%), Daniels Scale $(11 \%)$, reduced lunch $(4 \%)$, and other measures (e.g., subsidized housing). Studies of which authors did not send in their categorization were categorized based on characteristics of SES as reported in the articles, such as educational level (43\%), income (27\%), Hollingshead index $(23 \%)$, employment rates $(13 \%)$, and other measures (e.g., subsidized housing). Two coders categorized all studies independently of the original authors categorization, which showed sufficient reliability with the original authors' categorization (Cohen's $\kappa=.74$ ).

Initial problem severity. Initial problem severity scores for each study were based on pretreatment scores of disruptive behavior. To make study findings comparable, we indexed levels of initial problem severity by the number of standard deviations that the initial problem severity score reported in a particular study deviated from existing norms for the instrument used. More specifically, we computed norm-deviation scores by subtracting from each study's pretreatment score the instrument's normative score and dividing this difference by the instrument's normative standard deviation. For example, Funderburk et al. (1998) reported a baseline disruptive behavior score on the Eyberg Child Behavior Inventory of 169.90. The Eyberg Child Behavior Inventory norm score for this age range (2-7) and gender (100\% boys) is 109.82 , with a standard deviation of 27.38 (Burns \& Patterson, 2001). The Funderburk et al. norm-deviation score is therefore (169.90 109.82) $/ 27.38=2.19$ standard deviations from the normative mean. Questionnaires used for calculation of norm-deviation scores are the Eyberg Child Behavior Inventory (77\% of studies; Burns \& Patterson, 2001), Child Behavior Checklist (21\% of studies; Achenbach, 1991), Strengths and Difficulties Questionnaire (7\% of studies; National Center for Health Statistics, 2001), Parent Daily Report (6\% of studies; Chamberlain \& Reid, 1987), and Behavior Problem ChecklistPeterson-Quay (1\% of studies; Speer, 1971). Gender and age-specific norm scores were used when available. For example, if a norm score was 12 for males and 10 for females, and a sample included $60 \%$ males and $40 \%$ females, the norm score we used was $\left[\left(60^{*} 12\right)+\left(40^{*} 10\right)\right] / 100=11.20$. If studies used multiple instruments of disruptive behavior, a mean normdeviation score of the individual instruments' norm-deviation scores was computed. Calculations of norm-deviation scores for individual studies are available from the authors on request.

\section{Reliability}

All studies were coded by the first author. A random sample of $20 \%$ of the studies was coded by a trained graduate student. Intraclass correlation alphas and Cohen's kappas were computed for continuous and dichotomous data, respectively. Interrater reliability was good with alphas ranging from .86 to $1(M=.96)$ and kappas ranging from .76 to $1(M=.89)$.

\section{RESULTS}

\section{Meta-Analytic Strategy}

Table 1 shows an overview of the studies in the present meta-analysis. Hierarchical analyses were conducted following the method of Lipsey and Wilson (2001), with studies weighted by their inverse variance (comparable 
TABLE 1

Study Descriptives

\begin{tabular}{|c|c|c|c|c|c|c|c|}
\hline Study & $N$ & Program & $R C T$ & SES & $\begin{array}{c}\text { Intial Problem Severity } \\
\text { (Norm-Deviance } \\
\text { Expressed in } S D)\end{array}$ & $\begin{array}{c}\text { Cohen's d (Immediate } \\
\text { Posttreatment; } \\
\text { Intergroup) }\end{array}$ & $\begin{array}{l}\text { Cohen's d } \\
\text { (Follow-Up; } \\
\text { Intragroup) }\end{array}$ \\
\hline Barkley et al. (1996) & 81 & BPT & $\mathrm{RCT}$ & ND & 1.61 & -.07 & \\
\hline Bodenmann et al. (2008) & 100 & Triple-P & $\mathrm{RCT}$ & $\mathrm{D}$ & .49 & .25 & .10 \\
\hline Bor et al. (2002) & 42 & Triple-P & $\mathrm{RCT}$ & ND & 2.08 & .89 & \\
\hline Bor et al. (2002) & 48 & Triple-P & $\mathrm{RCT}$ & ND & 1.98 & 1.00 & \\
\hline Braet et al. (2009) & 49 & BPT & RCT & ND & 2.1 & -.01 & .37 \\
\hline Brotman et al. (2003) & 30 & IY & $\mathrm{RCT}$ & $\mathrm{D}$ & .31 & .71 & \\
\hline Connell et al. (1997) & 23 & BPT & $\mathrm{RCT}$ & ND & .86 & 1.61 & 1.85 \\
\hline Connolly et al. (2001) & 45 & IY & Q-E & ND & 1.45 & .16 & .49 \\
\hline Cunningham et al. (1995) & 78 & BPT & $\mathrm{RCT}$ & ND & .87 & & .07 \\
\hline Cunningham et al. (1995) & 77 & $\mathrm{BPT}$ & RCT & ND & .87 & & -.02 \\
\hline Edwards et al. (2007) & 116 & IY & $\mathrm{RCT}$ & $\mathrm{D}$ & 1.16 & .57 & \\
\hline Eyberg et al. (1995) & 16 & PCIT & $\mathrm{RCT}$ & $\mathrm{D}$ & 1.99 & 1.50 & \\
\hline Firestone et al. (1980) & 18 & BPT & $\mathrm{RCT}$ & ND & 1.31 & .82 & .69 \\
\hline Funderburk et al. (1998) & 84 & PCIT & Q-E & ND & 2.19 & 1.32 & \\
\hline Gallart \& Matthey (2005) & 33 & Triple-P & $\mathrm{RCT}$ & $\mathrm{D}$ & .50 & .57 & \\
\hline Gallart \& Matthey (2005) & 32 & Triple-P & RCT & $\mathrm{D}$ & .64 & .57 & \\
\hline Gardner et al. (2006) & 71 & IY & $\mathrm{RCT}$ & $\mathrm{D}$ & 1.72 & .52 & .73 \\
\hline Gross et al. (2003) & 134 & IY & $\mathrm{RCT}$ & $\mathrm{D}$ & -.17 & -.05 & .05 \\
\hline Hahlweg et al. (2009) & 63 & Triple-P & $\mathrm{RCT}$ & ND & 1.06 & .58 & \\
\hline Hamilton \& MacQuiddy (1984) & 18 & BPT & $\mathrm{RCT}$ & ND & 1.29 & 1.56 & 2.02 \\
\hline Hamilton \& MacQuiddy (1984) & 18 & BPT & $\mathrm{RCT}$ & ND & 1.32 & .77 & .95 \\
\hline Helfenbaum-Kun \& Ortiz (2007) & 39 & IY & RCT & $\mathrm{D}$ & -.51 & .83 & \\
\hline Hutching et al. (2007) & 153 & IY & $\mathrm{RCT}$ & $\mathrm{D}$ & 1.22 & .61 & \\
\hline Larsson et al. (2009) & 75 & IY & $\mathrm{RCT}$ & ND & 1.31 & .58 & 1.36 \\
\hline Lavigne et al. (2008) & 91 & IY & $\mathrm{RCT}$ & ND & 1.71 & .15 & \\
\hline Leung et al. (2003) & 88 & Triple-P & $\mathrm{RCT}$ & ND & 1.00 & .67 & \\
\hline Markie-Dadds \& Sanders (2006a) & 25 & Triple-P & $\mathrm{RCT}$ & ND & 1.29 & 1.64 & 1.95 \\
\hline Markie-Dadds \& Sanders (2006a) & 43 & Triple-P & RCT & ND & 1.63 & .75 & 1.38 \\
\hline Markie-Dadds \& Sanders (2006b) & 27 & Triple-P & RCT & ND & .98 & .88 & 1.14 \\
\hline Matsumoto et al. (2007) & 50 & Triple-P & $\mathrm{RCT}$ & ND & .02 & .61 & \\
\hline McNeil et al. (1999) & 32 & PCIT & Q-E & ND & 2.21 & 1.79 & \\
\hline McNeil et al. (1991) & 20 & PCIT & Q-E & ND & 2.37 & .90 & \\
\hline Morawska \& Sanders (2006) & 31 & Triple-P & $\mathrm{RCT}$ & ND & .33 & .60 & .75 \\
\hline Morawska \& Sanders (2006) & 30 & Triple-P & $\mathrm{RCT}$ & ND & .30 & .63 & .35 \\
\hline Mullin \& Quigley (1994) & 79 & EHB & Q-E & ND & .00 & .25 & \\
\hline Myers et al. (1992) & 81 & ЕВPР & Q-E & $\mathrm{D}$ & 1.06 & .51 & -.11 \\
\hline Niccols (2009) & 71 & $\mathrm{COPE}^{a}$ & $\mathrm{RCT}$ & ND & .21 & -.02 & .17 \\
\hline B. Nicholson et al. (2002) & 26 & STAR & $\mathrm{RCT}$ & $\mathrm{D}$ & 1.02 & .30 & .49 \\
\hline J. M. Nicholson \& Sanders (1999) & 42 & BPT & $\mathrm{RCT}$ & ND & -.15 & .67 & \\
\hline Nixon (2001) & 34 & PCIT & $\mathrm{RCT}$ & ND & .57 & .77 & 2.04 \\
\hline Nixon et al. (2003) & 41 & PCIT & RCT & ND & .37 & .46 & .78 \\
\hline Nixon et al. (2003) & 40 & PCIT & $\mathrm{RCT}$ & ND & .28 & .66 & 1.02 \\
\hline Ogden \& Hagen (2008) & 112 & PMTO & $\mathrm{RCT}$ & ND & 1.32 & .19 & \\
\hline Packard et al. (1983) & 18 & $\mathrm{BPT}$ & $\mathrm{RCT}$ & ND & -.34 & .00 & \\
\hline Packard et al. (1983) & 18 & BPT & $\mathrm{RCT}$ & ND & -.33 & .00 & \\
\hline G. R. Patterson et al. (1982) & 19 & BPT & RCT & ND & -.69 & .00 & \\
\hline J. Patterson et al. (2002) & 116 & IY & $\mathrm{RCT}$ & ND & .48 & .24 & .37 \\
\hline Sanders, Markie-Dadds, et al. (2000) & 136 & Triple-P & $\mathrm{RCT}$ & ND & 1.34 & .65 & 1.00 \\
\hline Sanders, Markie-Dadds, et al. (2000) & 132 & Triple-P & $\mathrm{RCT}$ & ND & 1.17 & .34 & .70 \\
\hline Sanders, Markie-Dadds, et al. (2000) & 129 & Triple-P & $\mathrm{RCT}$ & ND & 1.30 & .85 & .94 \\
\hline Sanders, Montgomery, et al. (2000) & 56 & Triple-P & $\mathrm{RCT}$ & ND & .58 & .77 & .83 \\
\hline Sayger et al. (1988) & 43 & $\mathrm{BPT}$ & RCT & ND & 2.16 & .91 & \\
\hline Schuhmann et al. (1998) & 64 & PCIT & RCT & $\mathrm{D}$ & 2.09 & 1.09 & \\
\hline M. J. Scott \& Stradling (1987) & 56 & SPP & Q-E & $\mathrm{D}$ & 1.25 & 1.14 & \\
\hline S. Scott et al. (2001) & 110 & IY & Q-E & ND & 2.32 & .89 & \\
\hline S. Scott et al. (2010) & 112 & IY & $\mathrm{RCT}$ & $\mathrm{D}$ & .32 & .39 & \\
\hline Sheeber \& Johnson (1994) & 41 & BPT & RCT & ND & 1.22 & .53 & .72 \\
\hline
\end{tabular}


TABLE 1

Continued

\begin{tabular}{|c|c|c|c|c|c|c|c|}
\hline Study & $N$ & Program & $R C T$ & SES & $\begin{array}{c}\text { Intial Problem Severity } \\
\text { (Norm-Deviance } \\
\text { Expressed in SD) }\end{array}$ & $\begin{array}{c}\text { Cohen's d (Immediate } \\
\text { Posttreatment; } \\
\text { Intergroup) }\end{array}$ & $\begin{array}{l}\text { Cohen's d } \\
\text { (Follow-Up; } \\
\text { Intragroup) }\end{array}$ \\
\hline Spaccarelli et al. (1992) & 32 & IY & $\mathrm{RCT}$ & ND & .91 & .70 & \\
\hline Spaccarelli et al. (1992) & 37 & IY & $\mathrm{RCT}$ & ND & .91 & 1.13 & \\
\hline Taylor et al. (1998) & 64 & IY & Q-E & ND & 1.26 & .50 & \\
\hline Thorell (2009) & 82 & $\mathrm{COPE}^{b}$ & Q-E & ND & -.15 & .39 & \\
\hline Turner et al. (2007) & 51 & Triple-P & $\mathrm{RCT}$ & D & 1.28 & .50 & .71 \\
\hline Turner \& Sanders (2006) & 30 & Triple-P & RCT & ND & .80 & .44 & \\
\hline Webster-Stratton (1982) & 35 & IY & $\mathrm{RCT}$ & ND & .18 & .45 & .65 \\
\hline Webster-Stratton (1984) & 24 & IY & $\mathrm{RCT}$ & ND & 1.58 & .99 & 1.50 \\
\hline Webster-Stratton (1984) & 22 & IY & $\mathrm{RCT}$ & ND & 1.76 & 1.15 & 1.79 \\
\hline Webster-Stratton (1990) & 33 & IY & $\mathrm{RCT}$ & ND & 1.66 & .47 & \\
\hline Webster-Stratton (1990) & 33 & IY & $\mathrm{RCT}$ & ND & 1.48 & .46 & \\
\hline Webster-Stratton (1992) & 100 & IY & $\mathrm{RCT}$ & ND & 1.59 & .55 & 1.16 \\
\hline Webster-Stratton \& Hammond (1997) & 48 & IY & $\mathrm{RCT}$ & ND & 1.65 & 1.01 & 1.27 \\
\hline Webster-Stratton et al. (1988) & 54 & IY & $\mathrm{RCT}$ & ND & 1.60 & .54 & \\
\hline Webster-Stratton et al. (1988) & 54 & IY & $\mathrm{RCT}$ & ND & 1.60 & .74 & \\
\hline Webster-Stratton et al. (1988) & 51 & IY & $\mathrm{RCT}$ & ND & 1.62 & .55 & \\
\hline Wiggins et al. (2009) & 60 & Triple-P & RCT & ND & 1.52 & .50 & .73 \\
\hline Zangwill (1983) & 11 & PCIT & $\mathrm{RCT}$ & $\mathrm{D}$ & 1.90 & 2.03 & \\
\hline
\end{tabular}

Note: $\mathrm{RCT}=$ randomized allocation to conditions; $\mathrm{SES}=$ socioeconomic status; $\mathrm{BPT}=$ Behavioral Parent Training, no official program name reported; $\mathrm{ND}=$ nondisadvantaged sample; Triple $\mathrm{P}=$ Triple-P Positive Parenting Program; $\mathrm{D}=$ disadvantaged sample; IY $=$ Incredible Years; $\mathrm{Q}-\mathrm{E}=$ quasi-experimental design with nonrandom allocation to conditions; PCIT $=$ Parent-Child Interaction Therapy; EHB = Eastern Health Board Parenting Program; EBPP $=$ Effective Black Parenting Program; $\mathrm{COPE}^{a}=$ COPEing with Toddler Behaviour; STAR $=$ STAR Parenting Program; $\mathrm{PMTO}=$ Parent Management Training-Oregon Model; SPP $=$ Scott Parent Programme; $\mathrm{COPE}^{b}=$ Community Parent Education Program.

to sample size). In Step 1 of the analysis, we entered SES and initial problem severity as predictors of effect size. In Step 2, we added the Initial Problem Severity $\times$ SES interaction. Both steps were separately conducted for immediate posttreatment and follow-up assessment.

\section{Immediate Posttreatment Effects of SES}

SES - controlled for initial problem severity - did not predict effect sizes of parent training effectiveness immediately posttreatment $(\beta=-.04, n s)$. Thus directly after the end of the intervention, disadvantaged samples and nondisadvantaged samples benefited equally from parent training. However, SES did interact with initial problem severity in predicting effect sizes of parent training effectiveness $(\beta=-.36, p<.001)$, such that

TABLE 2

Means and Standard Deviations for the Variables That Did Not Influence the Effects of Socioeconomic Status and Initial Problem Severity on Parent Training Program Effectiveness

\begin{tabular}{lcl}
\hline & Range & $M(S D)$ \\
\hline$\%$ of Drop-Out Families & $0-77.78$ & $16.16(16.02)$ \\
No. of Program Sessions & $2-60$ & $11.58(7.16)$ \\
Average No. of Attended Sessions & $2-21.23$ & $10.16(3.59)$ \\
\hline
\end{tabular}

disadvantaged samples benefited less from parent training, but only when they had low levels of initial problem severity (see Figure 1). So when initial problems were severe, disadvantaged and nondisadvantaged families benefited equally, but when initial problems were mild, disadvantaged families benefited less. As expected, there was a direct link between initial problem severity and parent training effectiveness, with higher effect sizes in samples with more severe initial problems $(\beta=.47$, $p<.001)$.

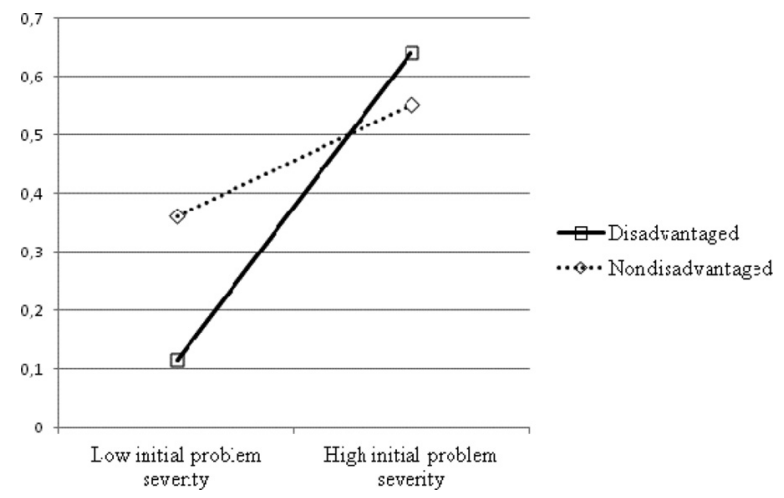

FIGURE 1 Effects of initial problem severity on immediate posttreatment effectiveness are especially meaningful in disadvantaged samples. 


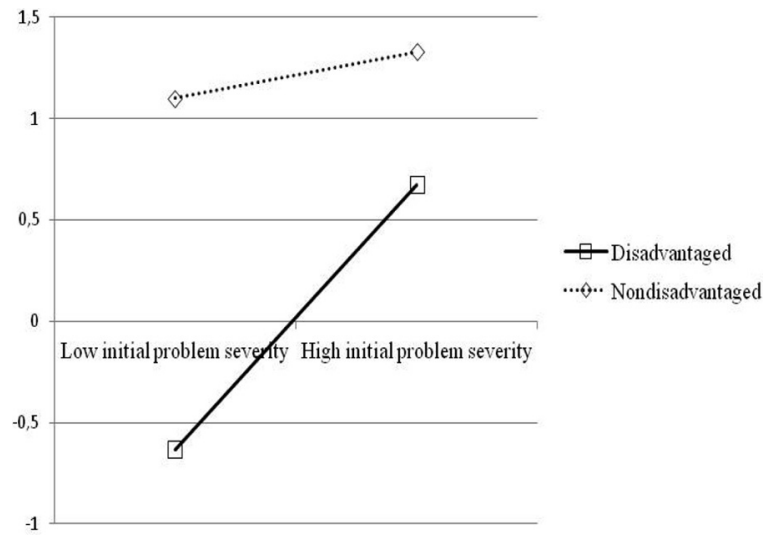

FIGURE 2 Effects of socioeconomic status are not moderated by effects of initial problem severity on parent training effectiveness at follow-up.

\section{Follow-Up Effects of SES}

SES - controlled for initial problem severity — predicted intragroup effect sizes of parent training effectiveness at follow-up $(\beta=.30, p<.001)$. Approximately one year after the end of treatment, disadvantaged samples benefited less than nondisadvantaged samples from parent training. There was no significant SES $\times$ Initial Problem Severity interaction effect $(\beta=-.13, n s)$ at follow-up, meaning that approximately one year after parent training, disadvantaged families benefited less regardless of initial problem severity (see Figure 2). Much like the finding at immediate posttreatment, there was a direct link between initial problem severity and parent training effectiveness at follow-up, with higher effect sizes in samples with more severe initial problems $(\beta=.41, p<.001)$.

For all analyses, results were not influenced by design of random or nonrandom assignment to conditions, drop-out rates, absolute dose of treatment (i.e., number of sessions in the program), relative dose of treatment (i.e., attendance rates), or questionnaire type used for computing the norm-deviation scores (e.g., Eyberg Child Behavior Inventory, Child Behavior Checklist). Effects of initial problem severity, the SES $\times$ Initial Problem Severity interaction immediately posttreatment, and SES at follow-up remained significant $(p s<.05)$. Effects of SES immediately posttreatment and the SES $\times$ Initial Problem Severity interaction at follow-up remained nonsignificant $(p s>.05)$. Please see Tables 1 and 2 for descriptions of the studies' designs, drop-out rates, and treatment doses.

\section{DISCUSSION}

Although disadvantaged SES is assumed to diminish parent training effectiveness, hardly anything is known on how effects of SES are influenced by effects of initial prob- lem severity - a well-known predictor of parent training effectiveness (e.g., Deković et al., 2011) and related to SES (e.g., Wadsworth \& Achenbach, 2005). In the present meta-analysis, we examined whether SES - controlled for initial problem severity-influenced parent training effectiveness at immediate posttreatment and at follow-up approximately one year later. In addition, we examined whether SES interacted with initial problem severity such that effects of initial problem severity were especially meaningful in disadvantaged families.

Our results show that when controlling for initial problem severity, disadvantaged SES diminishes immediate postparent training effectiveness only when initial problem behaviors are mild. When initial problem behaviors are severe (i.e., reach clinical norms), disadvantaged and nondisadvantaged samples benefit equally. The absence of a direct effect of SES immediately posttreatment is in line with some previous meta-analytic work (e.g., Serketich \& Dumas, 1996), and in contrast with others (e.g., Lundahl et al., 2006).

SES predicts parent training effectiveness at follow-up. Disadvantaged samples show less improvement 1 year after the end of treatment, regardless of initial problem severity. This finding indicates that disadvantaged samples experience more trouble maintaining positive treatment outcomes. Chronic stressors that accompany their disadvantaged SES, such as limited economic resources and neighborhood poverty, may become especially salient after the end of parent training programs when guidance from trainers on daily parenting situations is no longer available (e.g., Baum et al., 1999; Pinderhughes et al., 2001).

Initial problem severity predicts parent training effectiveness both immediately posttreatment and at follow-up, which is in accordance with previous findings (e.g., Deković et al., 2011; Hautmann et al., 2010). Parent training programs are most effective for families with highly disruptive children at the start of intervention, which may be explained by more motivation to change in these families and larger scopes of improvement (Baydar et al., 2003). Treatment studies in clinical samples generally obtain stronger effects than preventive studies in nonclinical, community samples (Weisz et al., 2005). Our findings build on this work, and show that the difference between treatment and prevention effects becomes especially salient in disadvantaged samples. It may be that families' readiness to change - an important predictor of treatment effectiveness (e.g., Miller \& Rollnick, 2002) - is lower in disadvantaged families with mild child behavior problems than in nondisadvantaged families with mild child behavior problems. In contrast, when child behavior problems are severe, disadvantaged and nondisadvantaged families benefit equally from parent training, at least immediately after the end of the intervention. 


\section{Strengths, Limitations, and Implications}

Our meta-analysis builds on previous meta-analytic work by integrating effects of SES and initial problem severity and by directly comparing immediate posttreatment and follow-up parent training effectiveness. In doing so, we were able to show that immediately posttreatment, SES diminishes parent training effectiveness only when initial problems are mild, whereas at follow-up SES diminishes parent training effectiveness regardless of initial problem severity.

Several limitations should be taken into consideration when interpreting our results. The quality of all meta-analyses depends on the characteristics of the available empirical studies. Ours was no exception. Follow-up measures were not available in all studies included in our meta-analysis (see Table 1), and therefore we cannot exclude the possibility that there is some selection bias in the follow-up results. This said, no differences were found between follow-up and non-follow-up studies on the key study variables (i.e., SES, initial problem severity, and immediate posttreatment effect size), suggesting that selection bias was not a major problem. Also, the need to use intragroup effect sizes at follow-up (instead of intergroup effect sizes, because most studies had no follow-up assessment of the control group) resulted in inflated effect sizes for follow-up effectiveness. Follow-up effect sizes can therefore only be compared with each other and not with immediate posttreatment effect sizes.

Our results have implications for future research and clinical practice. Parent training programs seem beneficial for both disadvantaged and nondisadvantaged families, at least immediately posttreatment, and especially for families with high levels of initial problem severity. However, the finding that disadvantaged families benefit less immediately posttreatment when initial behavior problems are mild asks for future research to examine possible explanations for this effect. Perhaps motivation to change is more problematic in disadvantaged families with mild initial problems, and if so, this would suggest that in clinical practice more attention for "readiness to change" might needed in parent training programs for disadvantaged families (e.g., Miller \& Rollnick, 2002). Moreover, the finding that disadvantaged families benefit less from parent training 1 year later raises the question for future research why disadvantaged families are less able to maintain treatment effects. For clinical practice, this finding suggests that more sustained support after the intervention might be needed for disadvantaged families.

\section{REFERENCES}

References marked with an asterisk indicate studies included in the meta-analysis.

Achenbach, T. M. (1991). Manual for the Child Behavior Checklist/ 4-J8 and 1991 profile. Burlington: University of Vermont, Department of Psychiatry.
*Barkley, R. A., Shelton, T. L., Crosswait, C., Moorehouse, M., Fletcher, K., Barrett, S., ... Metevia, L. (1996). Preliminary findings of an early intervention program with aggressive hyperactive children. Annals of the New York Academy of Sciences, 794, 277-289.

Baum, A., Garofalo, J. P., \& Yali, A. M. (1999). Socioeconomic status and chronic stress: Does stress account for SES effects on health? Annals of the New York Academy of Sciences, 896, 131-144.

Baydar, N., Reid, M. J., \& Webster-Stratton, C. (2003). The role of mental health factors and program engagement in the effectiveness of a preventive parenting program for Head Start mothers. Child Development, 74, 1433-1453.

*Bodenmann, G., Cina, A., Ledermann, T., \& Sanders, M. R. (2008). The efficacy of the Triple P-Positive Parenting Program in improving parenting and child behavior: A comparison of two other treatment conditions. Behaviour Research and Therapy, 46, 411-427.

${ }^{*}$ Bor, W., Sanders, M. R., \& Markie-Dadds, C. (2002). The effects of the Triple P-Positve Parenting Program on preschool children with co-occurring disruptive behavior and attentional/hyperactive difficulties. Journal of Abnormal Child Psychology, 30, 571-589.

Bradley, R. H., Corwyn, R. F., Burchinal, M., McAdoo, H. P., \& Garcia-Coll, C. (2001). The home environment of children in the United States Part II: Relations with behavioral development through age thirteen. Child Development, 72, 1868-1886.

*Braet, C., Meerschaert, T., Merlevede, E., Bosmans, G., Van Leeuwen, K., \& De Mey, W. (2009). Prevention of antisocial behaviour: Evaluation of an early intervention programme. European Journal of Developmental Psychology, 6, 223-240.

*Brotman, L. M., Klein, R. G., Kamboukos, D., Brown, E. J., Coard, S. I., \& Sosinsky, L. S. (2003). Preventive intervention for urban, low-income preschoolers at familial risk for conduct problems: A randomized pilot study. Journal of Clinical Child and Adolescent Psychology, 32, 246-257.

Burns, G. L., \& Patterson, D. R. (2001). Normative data on the Eyberg Child Behavior Inventory and Sutter-Eyberg Student Behavior Inventory: Parent and teacher rating scales of disruptive behavior problems in children and adolescents. Child \& Family Behavior Therapy, 23, 15-28.

Chamberlain, P., \& Reid, J. B. (1987). Parent observation and report of child symptoms. Behavioral Assessment, 9, 97-109.

Conger, R. D., Conger, K. J., Elder, G. H., Jr., Lorenzo, F. O., Simons, R. L., \& Whitbeck, L. B. (1992). A family process model of economical hardship and adjustment of early adolescent boys. Child Development, 63, 526-541.

${ }^{*}$ Connell, S., Sanders, M. R., \& Markie-Dadds, C. (1997). Selfdirected behavioral family intervention for parents of oppositional children in rural and remote areas. Behavior Modification, 21, 379-408.

${ }^{*}$ Connolly, L., Sharry, J., \& Fitzpatrick, C. (2001). Evaluation of a group treatment programme for parents of children with behavioural disorders. Child Psychology and Psychiatry Review, 6, 159-165.

${ }^{*}$ Cunningham, C. E., Bremner, R., \& Boyle, M. (1995). Large group community-based parenting programs for families of preschoolers at risk for disruptive behaviour disorders: Utilization, cost effectiveness, and outcome. Journal of Child Psychology and Psychiatry, 36, $1141-1159$.

Deković, M., Slagt, M. I., Asscher, J. J., Boendermaker, L., Eichelsheim, V. I., \& Prinzie, P. (2011). Effects of early prevention programs on adult criminal offending: A meta-analysis. Clinical Psychology Review, 31, 532-544.

*Edwards, R. T., Céilleachair, A., Bywater, T., Hughes, D. A., \& Hutchings, J. (2007). Parenting programme for parents of children at risk of developing conduct disorder: Cost effectiveness analysis. British Medical Journal, 334, 682-685.

Evans, G. W., Boxhill, L., \& Pinkava, M. (2008). Poverty and maternal responsiveness: The role of maternal stress and social resources. International Journal of Behavioral Development, 32, 232-237. 
*Eyberg, S. M., Boggs, S. R., \& Algina, J. (1995). Parent-Child Interaction Therapy: A psychosocial model for the treatment of young children with conduct problem behavior and their families. Psycho pharmacology Bulletin, 31, 83-91.

${ }^{*}$ Firestone, P., Kelly, M. J., \& Filke, S. (1980). Are fathers necessary in parent training groups? Journal of Child Clinical Psychology, 9, 44- 47.

*Funderburk, B. W., Eyberg, S. M., Newcomb, K., McNeil, C. B., Hembree-Kigin, T., \& Capage, L. (1998). Parent-Child Interaction Therapy with behavior problem children: Maintenance of treatment effects in the school setting. Child \& Family Behavior Therapy, 20, 17-38.

${ }^{*}$ Gallart, S. C., \& Matthey, S. (2005). The effectiveness of group Triple $\mathrm{P}$ and the impact of the four telephone contacts. Behaviour Change, $22,71-80$.

${ }^{*}$ Gardner, F., Burton, J., \& Klimes, I. (2006). Randomised controlled trial of a parenting intervention in the voluntary sector for reducing child conduct problems: Outcomes and mechanisms of change. Journal of Child Psychology and Psychiatry, 47, 1123-1132.

Gardner, F., Hutchings, J., Bywater, T., \& Whitaker, C. (2010). Who benefits and how does it work? Moderators and mediators of outcome in an effectiveness trial of a parenting intervention. Journal of Clinical Child and Adolescent Psychology, 39, 568-580.

${ }^{*}$ Gross, D., Fogg, L., Webster-Stratton, C., Garvey, C., Julion, W., \& Grady, J. (2003). Parent training of toddlers in day care in low-income urban communities. Journal of Consulting and Clinical Psychology, 71, 261-278.

*Hahlweg, K., Heinrichs, N., Kuschel, A., \& Feldmann, M. (2009). Therapist assisted self-administered bibliotherapy to enhance parental competence: Short- and long-term effects. Behavior Modification, 32, 659-681.

${ }^{*}$ Hamilton, S., \& MacQuiddy, S. L. (1984). Self-administered behavioral parent training: Enhancement of treatment efficacy using a time-out signal seat. Journal of Clinical Child Psychology, 13, 61-69.

Hautmann, C., Eichelberger, I., Hanisch, C., Plück, J., Walter, D., \& Döpfner, M. (2010). The severely impaired do profit most: Short-term and long-term predictors of therapeutic change for a parent management training under routine care conditions for children with externalizing problem behavior. European Child and Adolescent Psychiatry, 19, 419-430.

${ }^{*}$ Helfenbaum-Kun, E. D., \& Ortiz, C. (2007). Parent-training groups for fathers of Head Start children: A pilot study of their feasibility and impact on child behavior and intrafamilial relationships. Child \& Family Behavior Therapy, 29, 47-64.

${ }^{*}$ Hutching, J., Bywater, T., Daley, D., Gardner, F., Whitaker, C., Jones, K., ... Edwards, R. T. (2007). Parenting intervention in Sure Start services for children at risk of developing conduct disorder: Pragmatic rondomised controlled trial. British Medical Journal, 337, 678-684.

${ }^{*}$ Larsson, B., Fossum, S., Clifford, G., Drugli, M. B., Handegard, B. H., \& Mørch, W. T. (2009). Treatment of oppositional defiant and conduct problems in young Norwegian children. European Child and Adolescent Psychiatry, 18, 42-50.

*Lavigne, J. V., LeBailly, S. A., Grouze, K. R., Cicchetti, C., Jessup, B. W., Arend, R., ... Binns, H. J. (2008). Predictor and moderator effects in the treatment of oppositional defiant disorder in pediatric primary care. Journal of Pediatric Psychology, 33, 462-472.

${ }^{*}$ Leung, C., Sanders, M. R., Leung, R. M., \& Lau, J. (2003). An outcome evaluation of the implementation of the Triple P-Positive Parenting Program in Hong Kong. Family Process, 42, 531-544.

Lipsey, M. W., \& Wilson, D. B. (2001). Practical meta-analysis. Thousand Oaks, CA: Sage.

Lundahl, B., Risser, H. J., \& Lovejoy, M. C. (2006). A meta-analysis of parent training: Moderators and follow-up effects. Clinical Psychology Review, 26, 86-104.

Maas, C. J. M., \& Hox, J. J. (2005). Sufficient sample sizes for multilevel modeling. Methodology: European Journal of Research Methods for the Behavioral and Social Sciences, 1, 86-92.
MacKenzie, E. P., Fite, P. J., \& Bates, J. E. (2004). Predicting outcome in behavioral parent training: Expected and unexpected results. Child \& Family Behavior Therapy, 2, 37-53.

*Markie-Dadds, C., \& Sanders, M. R. (2006a). A controlled evaluation of an enhanced self-directed behavioural family intervention for parents of children with conduct problems in rural and remote areas. Behaviour Change, 23, 55-72.

*Markie-Dadds, C., \& Sanders, M. R. (2006b). Self-directed Triple P (Positive Parenting Program) for mothers with children at-risk for developing conduct problems. Behavioural and Cognitive Psychotherapy, 34, 259-275.

*Matsumoto, Y., Sofronoff, K., \& Sanders, M. R. (2007). The efficacy and acceptability of the Triple P-Positive Parenting Program with Japanese parents. Behaviour Change, 24, 205-218.

McCart, M. R., Priester, P. E., Davies, W. H., \& Azen, R. (2006). Differential effectiveness of behavior parent-training and cognitive behavioral therapy for antisocial youth: A meta-analysis. Journal of Abnormal Child Psychology, 34, 527-541.

${ }^{*}$ McNeil, C. B., Capage, L. C., Bahl, A., \& Blanc, H. (1999). Importance of early intervention for disruptive behavior problems: Comparison of treatment and waitlist-control groups. Early Education \& Development, 10, 445-454.

${ }^{*}$ McNeil, C. B., Eyberg, S., Eisenstadt, T. H., Newcomb, K., \& Funderburk, B. (1991). Parent-Child Interaction Therapy with behavior problem children: Generalization of treatment effects to the school setting. Journal of Clinical Child Psychology, 20, 140-151.

Miller, W. R., \& Rollnick, A. (Eds.). (2002). Motivational interviewing: Preparing people for change (2nd ed.). New York, NY: Guilford.

*Morawska, A., \& Sanders, M. R. (2006). Self-administered behavioral family intervention for parents of toddlers: Part 1. Efficacy. Journal of Consulting and Clinical Psychology, 74, 10-19.

* Mullin, E., \& Quigley, K. (1994). A controlled evaluation of the impact of a parent training programme on child behaviour and mothers' general well-being. Counselling Psychology Quarterly, 7, 167-197.

${ }^{*}$ Myers, H. F., Alvy, K. T., Arrington, A., Richardson, M. A., Marigna, M., Huff, R., ... Newcomb, M. D. (1992). The impact of a parent training program on inner-city African-American families. Journal of Community Psychology, 20, 132-148.

National Center for Health Statistics. (2001). Data file documentation, National Health Interview Survey. Hyattsville, MD: National Center for Health Statistics, Centers for Disease Control and Prevention.

*Niccols, A. (2009). Immediate and short-term outcomes of the 'COPEing with Toddler Behaviour' parent group. Journal of Child Psychology and Psychiatry, 50, 617-626.

*Nicholson, B., Anderson, M., Fox, R., \& Brenner, V. (2002). One family at a time: A prevention program for at-risk parents. Journal of Counselling and Development, 80, 362-371.

*Nicholson, J. M., \& Sanders, M. R. (1999). Randomized controlled trial of behavioral family intervention for the treatment of child behavior problems in stepfamilies. Journal of Divorce \& Remarriage, 30, 1-23.

${ }^{*}$ Nixon, R. D. V. (2001). Changes in hyperactivity and temperament in behaviourally disturbed preschoolers after Parent-Child Interaction Therapy. Behaviour Change, 18, 168-176.

*Nixon, R. D. V., Sweeney, L., Erickson, D. B., \& Touyz, S. W. (2003). Parent-Child Interaction Therapy: A comparison of standard and abbreviated treatments for oppositional defiant preschoolers. Behaviour Change, 18, 168-176.

*Ogden, T., \& Hagen, K. A. (2008). Treatment effectiveness of parent management training in Norway: A randomized controlled trial of children with conduct problems. Journal of Consulting and Clinical Psychology, 76, 607-621.

*Packard, T., Robinson, E. A., \& Grove, D. C. (1983). The effect of training procedures on the maintenance of parental relationship building skills. Journal of Clinical Child Psychology, 12, 181-186. 
*Patterson, G. R., Chamberlain, P., \& Reid, J. B. (1982). A comparative evaluation of a parent-training program. Behavior Therapy, 13, 638-650.

${ }^{*}$ Patterson, J., Barlow, J., Mockfor, C., Klimes, I., Pyper, C., \& Stewart-Brown, S. (2002). Improving mental health through parenting programmes: Block randomised controlled trial. Archives of Disease in Childhood, 87, 472-477.

Pinderhughes, E. E., Nix, R., Foster, E. M., \& Jones, D. (2001). Parenting in context: Impact of neighborhood poverty, residential stability, public services, social networks, and danger on parental behavior. Journal of Marriage and Family, 63, 941-953.

*Sanders, M. R., Markie-Dadds, C., Tully, L. A., \& Bor, W. (2000). The Triple P-Positive Parenting Program: A comparison of enhanced, standard, and self-directed behavioral family intervention for parents of children with early onset conduct problems. Journal of Consulting and Clinical Psychology, 68, 624-640.

*Sanders, M. R., Montgomery, D. T., \& Brechman-Toussaint, M. L. (2000). The mass media and the prevention of child behaviour problems: The evaluation of a television series to promote positive outcomes for parents and their children. Journal of Child Psychology and Psychiatry, 41, 939-948.

* Sayger, T. V., Horne, A. M., Walker, J. M., \& Passmore, J. L. (1988). Social learning family therapy with aggressive children: Treatment outcome and maintenance. Journal of Family Psychology, 1, 261-285.

Schonberg, M. A., \& Shaw, D. S. (2007). Do predictors of child conduct problems vary by high- and low-levels of socioeconomic and neighborhood risk? Clinical Child and Family Psychology, 10, 101-136.

*Schuhmann, E. M., Foote, R. C., Eyberg, S. M., Boggs, S. R., \& Algina, J. (1998). Efficacy of Parent-Child Interaction Therapy: Interim report of a randomized trial with short-term maintenance. Journal of Clinical Child Psychology, 27, 34-45.

*Scott, M. J., \& Stradling, S. G. (1987). Evaluation of a group programme for parents of problem children. Behavioural Psychotherapy, 15, 224-239.

*Scott, S., Spender, Q., Doolan, M., Jacobs, B., \& Aspland, H. (2001). Multicentre controlled trial of parenting groups for childhood antisocial behaviour in clinical practice. British Medical Journal, 323, 194-198.

*Scott, S., Sylva, K., Doolan, M., Price, J., Jacobs, B., Crook, C., \& Landau, S. (2010). Randomised controlled trial of parent groups for child antisocial behaviour targeting multiple risk factors: The SPOKES project. Journal of Child Psychology and Psychiatry, 51, 48-57.

Serketich, W. J., \& Dumas, J. E. (1996). The effectiveness of behavioral parent training to modify antisocial behavior in children: A meta-analysis. Behavior Therapy, 27, 171-186.

*Sheeber, L. B., \& Johnson, J. H. (1994). Evaluation of a temperament-focused, parent-training program. Journal of Clinical Child Psychology, 23, 249-259.

*Spaccarelli, S., Cotler, S., \& Penman, D. (1992). Problem-solving skills training as a supplement to behavioral parent training. Cognitive Therapy and Research, 16, 1-18.
Speer, D. C. (1971). Behavior problem checklist (Peterson-Quay) Base-line data from parents of child guidance and nonclinic children. Journal of Consulting and Clinical Psychology, 36, 221-228.

*Taylor, T. K., Schmidt, F., Pepler, D., \& Hodgins, C. (1998). A comparison of eclectic treatment with Webster-Stratton's Parents and Children Series in a children's mental health center: A randomized controlled trial. Behavior Therapy, 29, 221-240.

*Thorell, L. B. (2009). The Community Parent Education Program (COPE): Treatment effects in a clinical and a community-based sample. Clinical Child Psychology and Psychiatry, 14, 373-387.

*Turner, K. M. T., Richards, M., \& Sanders, M. R. (2007). Randomised clinical trial of a group parent education programme for Australian Indigenous families. Journal of Pediatrics and Child Health, 43, 429-437.

*Turner, K. M. T., \& Sanders, M. R. (2006). Help when it's needed first: A controlled evaluation of brief, preventive behavioral family intervention in a primary care setting. Behavior Therapy, 37, $131-142$.

Wadsworth, M. E., \& Achenbach, T. M. (2005). Explaining the link between low socioeconomic status and psychopathology: Testing two mechanisms of the social causation hypothesis. Journal of Consulting and Clinical Psychology, 73, 1146-1153.

*Webster-Stratton, C. (1982). The long-term effects of a videotape modelling parent-training program: Comparison of immediate and 1-year follow-up results. Behavior Therapy, 13, 702-714.

*Webster-Stratton, C. (1984). Randomized trial of two parent-training programs for families with conduct-disordered children. Journal of Consulting and Clinical Psychology, 52, 666-678.

*Webster-Stratton, C. (1990). Enhancing the effectiveness of self-administered videotape parent training for families with conduct-problem children. Journal of Abnormal Child Psychology, 18, 479-492.

*Webster-Stratton, C. (1992). Individually administered videotape parent training: "Who benefits?". Cognitive Therapy and Research, 16, 31-35.

*Webster-Stratton, C., \& Hammond, M. (1997). Treating children with early-onset conduct problems: A comparison of child and parent training interventions. Journal of Consulting and Clinical Psychology, 65, 93-109.

*Webster-Stratton, C., Kolpacoff, M., \& Hollinsworth, T. (1988). Self-administered videotape therapy for families with conduct-problem children: Comparison with two cost-effective treatments and a control group. Journal of Consulting and Clinical Psychology, 56, 558-566.

Weisz, J. R., Sandler, I. N., Durlak, J. A., \& Anton, B. S. (2005). Promoting and protecting youth mental health through evidence-based prevention and treatment. American Psychologist, 60, 628-648.

*Wiggins, T. L., Sofronoff, K., \& Sanders, M. R. (2009). Pathways Triple P-Positive Parenting Program: Effects of parent-child relationships and child behaviour problems. Family Process, 48, 517-530.

*Zangwill, W. M. (1983). An evaluation of a parent training program. Child and Family Behavior Therapy, 5, 1-6. 